\title{
Aglomerações produtivas e escolha de modal de transporte: um estudo de caso do setor industrial de São Paulo e Manaus
}

Productive agglomeration and transport modal choice: a case study of São Paulo and Manaus industrial sector

\author{
Eva Yamila da Silva Catela \\ Universidade Federal de Santa Catarina \\ Fernando Seabra \\ Universidade Federal de Santa Catarina
}

\begin{abstract}
The objective of this paper is to investigate the complementarity between two economic agglomerations (regions of São Paulo and Manaus) and to discuss the choice of the transportation mode between these two regions. São Paulo can be characterized as a mature and diversified agglomeration; while Manaus has a high specialization rate. Based on a proximity matrix, we can affirm that the two agglomerations have complementary production structures. As for the transportation network, trade occurs predominantly using the road-and-river mode and, in a smaller scale, using the short-sea shipping alternative. The migration potential for short-sea shipping is assessed by a discrete choice research. The results indicate that cargo migration depends on the characteristics of the transportation conditions (freights, transit time, service reliability and regularity) and on the production structure (such as aggregate value of the product and firm size).
\end{abstract}

\section{Keywords}

economic agglomeration; discrete choice research; short-sea shipping.

JEL Codes L23; L91; R49.

\section{Resumo}

O objetivo deste estudo é evidenciar a complementaridade entre duas aglomerações produtivas (microrregiões de São Paulo e Manaus) e discutir a escolha do modal de transporte entre essas duas regiões. São Paulo caracteriza-se como uma aglomeração produtiva madura e diversificada; enquanto Manaus detém uma forte especialização. A partir de uma matriz de proximidade, pode-se afirmar que as microrregiões apresentam estruturas de produção complementárias. Quanto à estrutura de transportes, o comércio ocorre principalmente via modal rodo-fluvial e, em menor parte, via cabotagem. O potencial de migração para cabotagem é avaliado por uma pesquisa de escolha discreta. Os resultados indicam que esta transferência depende de características da condição de transporte (fretes, transit time, confiabilidade e regularidade do serviço) e da estrutura produtiva (como valor agregado do produto e tamanho da empresa).

\section{Palavras-chave \\ aglomerações produtivas; pesquisa de escolha dis- creta; cabotagem.}

Códigos JEL L23; L91; R49. 


\section{Introdução}

A concentração espacial da atividade econômica ocorre como consequência do fato de que algumas regiões têm características que atraem uma maior quantidade de firmas que outras. A alocação espacial das atividades é resultado de um conjunto de forças que determinam que a localização de empresas não necessariamente coincide com a localização dos consumidores. Naturalmente, essa diferença geográfica de concentração de atividades de produção e de demanda resulta no ganho da importância dos custos de transporte na formação final dos preços dos bens.

A concentração das atividades de produção é determinada por diversos fatores: fontes de matérias-primas e recursos naturais, intervenção pública (subsídios), externalidades (distritos industriais), cercania dos centros consumidores e estrutura do setor de transportes e infraestrutura. A concentração espacial supõe um trade-off entre, de um lado, economias de escala na produção e, de outro, custo de transporte de bens, insumos e informação (Combes et al., 2012).

Neste contexto, este trabalho tem como objetivo mostrar que a alocação espacial da produção nas regiões Norte e Sudeste do Brasil, assim como a maior eficiência dessas alocações, impõe a necessidade de aperfeiçoar a escolha do modal de transporte por parte das empresas, o que depende, por sua vez, da existência de alternativas viáveis de serem utilizadas. Para isso, estuda-se o caso de duas microrregiões caracterizadas por forte concentração industrial assimétrica, Manaus (região Norte) e São Paulo (região Sudeste), relacionadas fortemente por fluxos de insumos, bens, serviços e trabalhadores. Os fluxos comerciais atuais ocorrem basicamente pelo modal rodoviário-fluvial, mas a cabotagem fluvial-marítimas se configura como uma opção relevante, se considerado o menor custo relativo de transporte e a abundância de vias naturais para uso desta última alternativa. ${ }^{1}$

Quanto à organização do estudo, a seção dois apresenta o instrumental teórico, discutindo as bases do modelo centro-periferia da nova geografia econômica (NEG) e da economia de redes, que explicam as forças de aglomeração e dispersão das atividades produtivas, assim como as conse-

1 A alternativa ferroviária não foi considerada na pesquisa empírica, dado que, se existem estudos considerando a viabilidade desse tipo de transporte na Amazônia (Freitas, 2009), eles não consideram o trecho Manaus -São Paulo, para o qual a cabotagem é considerada o meio de maior viabilidade econômica. 
quências da intervenção pública, através de políticas regionais. Na terceira seção, delineiam-se as características principais das aglomerações produtivas de Manaus e São Paulo, utilizando para isso uma medida de relevância industrial relativa e uma medida de proximidade das estruturas industriais de ambas as regiões.

Na quarta seção é utilizado um modelo logit misto, no sentido de captar o papel do transporte na configuração da localização ótima das aglomerações. Isso porque, por exemplo, um aumento da eficiência do modal de cabotagem poderia incentivar a localização de atividades produtivas na microrregião de Manaus, diminuindo a importância dos subsídios outorgados à Zona Franca de Manaus (ZFM). Assim, são expostos os resultados de uma pesquisa de escolha discreta, realizada junto a empresas de diversos setores econômicos das duas microrregiões estudadas, para entender os determinantes da escolha do modal de transporte. A escolha do modelo está associada à necessidade de considerar variáveis que mudam entre as alternativas dos diferentes modais (por exemplo, custo do frete e transit time) e outras que não mudam e estão associadas às características da empresa e do produto que ela fabrica e vende (por exemplo, tamanho da empresa, região geográfica, tipo de produto). A análise explícita da escolha de transporte é um avanço importante, se considerado que a localização da atividade econômica depende fortemente do tipo e do comportamento do setor de transporte que, por sua vez, depende da forma como a atividade econômica se distribui ao longo do espaço (Behrens; Picard, 2011). Conclui-se o trabalho com os comentários finais.

\section{Aglomerações produtivas, padrão de similaridade da estrutura produtiva e transporte}

Nesta seção, busca-se contribuir para o debate sobre a seguinte questão: o que determina a concentração industrial em um espaço geográfico? A distribuição geográfica da atividade econômica é extremamente desigual e obedece a forças que por um lado dispersam e por outro concentram tal atividade no espaço. No caso específico das microrregiões objeto deste estudo, as características que determinam as aglomerações são diferentes, porém, podem ser explicadas à luz da teoria da nova geografia econômica. 


\subsection{Aglomeração produtiva: determinantes}

O modelo pioneiro utilizado para explicar a concentração espacial, dentro da Nova Geografia Econômica (NEG)2 é o modelo centro-periferia (CP), que considera o caráter de autorreforço e articulação-ligação das aglomerações produtivas (Fujita et al., 1999), quando levamos em conta um setor moderno e outro tradicional.

Esses modelos explicam diferentes efeitos que conduzem o mecanismo básico da aglomeração. O primeiro é chamado de "efeito acesso ao mercado" que descreve a tendência das empresas a alocar a produção próxima aos centros consumidores e exportar para os mercados menores. $\bigcirc$ segundo efeito é o "efeito custo de vida", que estabelece o impacto da localização das firmas no custo de vida dos trabalhadores. Quanto maior a aglomeração de firmas, menor a necessidade de importar bens de outras regiões e menor o custo de vida. O último efeito é chamado de "efeito concentração de mercado", que reflete o fato de que firmas imperfeitamente competitivas têm a tendência de localizar-se em regiões com menor quantidade de concorrentes (Baldwin; Okubo, 2006).

Baldwin et al. (2003) mostram que os dois primeiros efeitos combinados com a migração inter-regional de trabalhadores criam o potencial de causalidade cumulativa que potencializa a aglomeração das atividades produtivas. A aglomeração aumenta a concorrência pelos consumidores, o que - a partir da tentativa de conquistar tais consumidores - tende a fazer com que as empresas reduzam os salários nominais relativos da região com maior aglomeração, gerando, assim, como consequência, uma força de dispersão. No limite, se as forças da aglomeração são mais fortes que as forças de dispersão, qualquer choque migratório pode disparar um ciclo que resulta no movimento da indústria e dos trabalhadores para uma única região.

Entre as variáveis que determinam ou limitam o peso relativo dessas forças está o custo de transporte, uma vez que a força que dispersa a atividade industrial é menor à medida que o transporte fica menos oneroso (dado que a concorrência de empresas de outras regiões é quase tão importante quanto à concorrência de firmas locais). No outro extremo, se o custo de transporte é muito alto, uma mudança no número de firmas locais três autores: Fujita (1988), Krugman (1991) e Venables (1996). 
terá um grande impacto na concorrência pelos consumidores e um grande efeito sobre os salários relativos.

As forças de aglomeração são menores se o custo de transporte é baixo, dado que o preço dos bens será similar nas regiões interligadas por esse baixo custo de transporte. Por outro lado, se o custo de transporte é alto, espera-se que a variedade de bens produzidos localmente tenha um forte impacto sobre o índice de preços. ${ }^{3}$ Porém, o resultado pode divergir se a diferença de tamanho entre as regiões é suficientemente grande (Takahashi, 2011) ou se os custos de transporte são assimétricos (Johdo, 2013). Logo, se os custos de transporte de uma região são suficientemente grandes - em relação a uma outra região, maior e com a qual exista ligações comerciais deverá existir um efeito de acesso de mercado para a região menor.

Os modelos originais, baseados em duas regiões e dois setores, exibem algumas limitações. De modo alternativo e complementar, estudos mais recentes enfatizam os efeitos de rede dentro de um sistema multirregional, com diferenciação de produtos, assimetrias de transporte, entre outras derivações - o que leva à possibilidade de múltiplos equilíbrios (Behrens; Thisse, 2007; Akamatsu et al., 2012).

Ottaviano (2011) enfatiza a importância da heterogeneidade dos consumidores e firmas na conformação do comportamento agregado da aglomeração. Se os consumidores desejam variedade, as firmas produzem bens diferenciados e existem custos de transporte, o equilíbrio de mercado envolve um percentual mais do que proporcional do setor de produtos diferenciados na região com maior percentual de gasto, exacerbando as diferenças exógenas do tamanho de mercado.

Sem considerar assimetrias de custo, e no contexto de um modelo multirregional, Akamatsu et al. (2012) consideram um processo evolucionário de padrão de aglomeração, no qual o parâmetro de custo de transporte decresce ao longo do tempo, ocasionando um processo de bifurcação do equilíbrio inicial, aumentando a força de aglomeração e instabilizando distribuições uniformes de produção.

Por sua vez, se uma das regiões concentra maior nível de atividades, concentra também melhor infraestrutura de transporte e os ganhos de escala geram custos menores. Isso afeta a força relativa que promove a

3 A diminuição da força de aglomeração/dispersão com a distância é resultado da lei de gravidade, que também determina o padrão de localização geográfica das empresas e dos trabalhadores. 
aglomeração de atividades produtivas (força centrípeta) e a força que promove a dispersão geográfica (força centrífuga), o que determinará o padrão geográfico da aglomeração (Takahashi, 2007).

\subsection{Políticas públicas regionais e aglomeração produtiva}

A decisão de localização de uma empresa é um processo não trivial definido por duas questões espaciais. Primeiro, existe um custo para deslocar bens e fatores produtivos ao longo do espaço geográfico. Segundo, é custoso fragmentar o processo produtivo devido à existência de retornos crescentes no nível da fábrica. Segundo Puga (2010), esse cenário causa um trade-off entre proximidade de mercado e concentração produtiva.

Tais características são incompatíveis com o paradigma da concorrência perfeita; e qualquer análise que tente explicar as interações do espaço geográfico e econômico deve considerar que o mecanismo de mercado não é capaz de oferecer um espaço econômico ótimo. A "questão espacial" (Ottaviano, 2011) implica que qualquer estudo de geografia econômica necessariamente deve levantar questões normativas. Essa questão é central para a política regional, dado que tem implicações para o bem-estar e para a distribuição da renda no espaço geográfico de um país.

O impacto das políticas regionais depende da extensão da integração comercial entre as regiões. Quanto menores as barreiras ao comércio, maior o impacto das intervenções públicas por meio de subsídios, infraestrutura e política de investigação e desenvolvimento. Ottaviano e Van Ypersele (2005) mostram que, quando as regiões diferem em termos de acesso ao mercado, a concorrência por subsídios entre as firmas "móveis" é um mecanismo eficiente de localização em comparação ao resultado de livre mercado. Contudo, deve ser salientado que se o diferencial dado pelo subsídio público é muito pronunciado, a localização de um número excessivo de firmas em regiões periféricas pode não ser um resultado ótimo.

Existe, assim, um efeito limiar que determina o ponto de quebra da aglomeração. Uma vez que existem diferenciais nas aglomerações regionais, o processo é reforçado por causalidade circular, o que produz rendas que tendem a manter o status quo da localização de firmas e fatores produtivos. A intervenção pública requer conhecer, previamente, o limiar do subsídio para que o espaço geográfico econômico mude. Brülhart et al. 
(2012) mostram que, se uma região quer atrair firmas, esta deve oferecer subsídios maiores que as rendas de aglomeração que as firmas usufruem na localização atual. Como corolário, existe um efeito "lock-in" que implica que mudanças temporárias de política de subsídios podem ter efeitos locacionais permanentes.

Por sua vez, o limiar do subsídio varia de acordo com o grau de desobstrução do comércio; isto é, à medida que os custos de comércio (custos de transporte) diminuem, fica mais fácil "roubar" a aglomeração (Ottaviano, 2011). Porém, se essa desobstrução é grande demais, existe uma possível indeterminação do equilíbrio de longo prazo, que pode ser solucionada pela intervenção política.

Essas ideias são resumidas na Figura 1 a seguir, adaptada de Baldwin et al. (2003). No eixo vertical é medido o retorno relativo à aglomeração entre a região central e a periférica. $\bigcirc$ eixo horizontal mostra o percentual de fator de produção móvel (capital) na região central. Suponha-se que os custos de transporte entre as regiões gerem uma curva de ganho relativo dada por $\Omega$, e um equilíbrio de quantidade de fator de produção capital no centro dado pelo ponto $\mathrm{E}$ e $\mathrm{K}_{\mathrm{CE}}$.

\section{Figura 1 Aglomeração e inovação no setor de transportes}

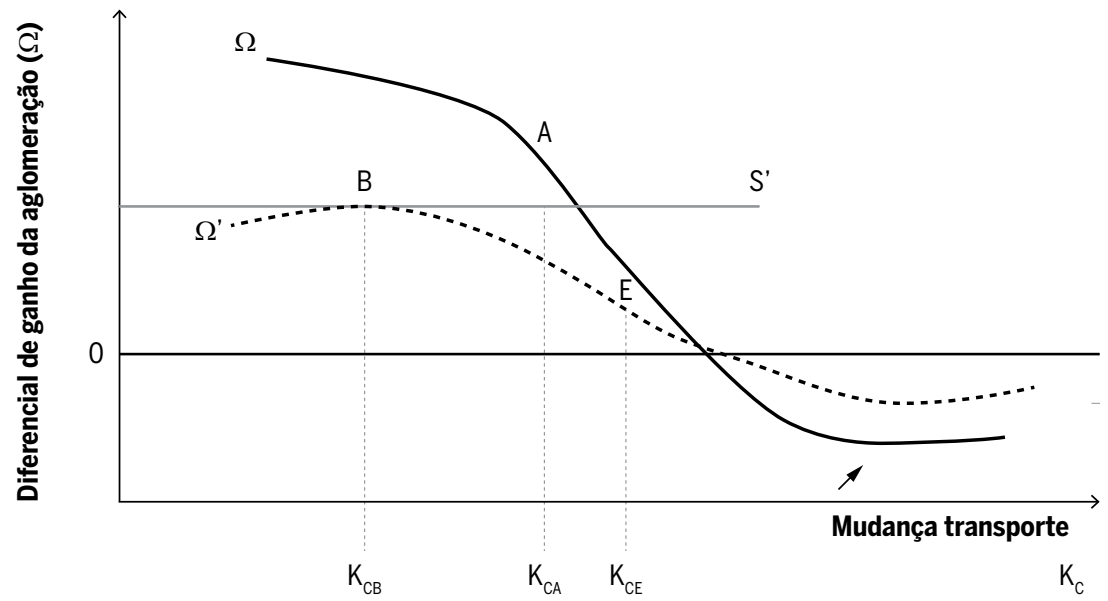

Fonte: adaptado de Baldwin et al. (2003).

Se for introduzido um subsídio de S' para o fator capital na região periférica, o ganho relativo dessa região aumenta, produzindo um deslocamento 
do fator de produção capital da região central para a periférica, ou seja, de E para $\mathrm{A}$ (e de $\mathrm{K}_{\mathrm{CE}}$ a $\mathrm{K}_{\mathrm{CA}}$ ). Se os custos de transporte são altos, a curva de ganho relativo para o fator capital é bastante inclinada e o subsídio provoca uma pequena transferência de fator capital. Se os custos de transportes são menores (linha pontilhada) - por causa, por exemplo, de inovação do setor, investimento em infraestrutura ou qualquer outra variável que faça com que os custos diminuam - a curva de ganho relativo fica menos inclinada e o mesmo nível de subsídio pode gerar um deslocamento maior do fator capital para a região periférica.

Assim, se tomamos como dado o nível de subsídio, somente mudanças na infraestrutura (incluindo transportes) podem ampliar o potencial de uma localização, conseguindo atrair atividades econômicas para ela (Behrens et al., 2009).

\subsection{Padrão de similaridade/complementariedade da estrutura produtiva}

Partindo do reconhecimento de que existem forças opostas determinantes das aglomerações produtivas e de que o custo de transporte e as políticas regionais de desenvolvimento influenciam a natureza dessas aglomerações, cabe mostrar outro efeito que também define o grau de interação das atividades produtivas entre as diferentes regiões. Trata-se do padrão de similaridade/complementariedade produtiva das diferentes regiões.

Fatores como efeitos spillovers espaciais e interdependências entre indústrias que utilizam algum fator de produção, insumo ou canal de distribuição comum implicam que a produção é mais eficiente ou menos custosa quando é espacialmente concentrada em setores com maior grau de similaridade. As empresas se beneficiam da proximidade de outras firmas que estão na mesma indústria ou são ofertantes (demandantes) dos seus insumos (produtos) (Cohen; Paul, 2005; Brown et al., 2013).

Audretsch e Feldman (2008) mostram que a localização e proximidade importam para explorar spillovers de conhecimento, favorecendo a inovação em empresas, especialmente em indústrias nas quais o gasto em $\mathrm{P} \& \mathrm{D}$, pesquisa universitária e trabalhadores qualificados são insumos de importância. Os autores demonstram que não necessariamente estes spillovers estão relacionados a firmas grandes ou economias de escala, dado que fir- 
mas grandes são mais adeptas a explorar conhecimentos criados nos seus próprios laboratórios.

Para analisar a relação e interdependência entre as regiões em análise, é importante conhecer a estrutura produtiva em termos de similaridade ou complementariedade. A medida de proximidade de Hausmann e Klinger (2007) permite conhecer a interconectividade entre indústrias dentro de umaestrutura produtiva. Os autores constroem uma matriz de proximidade para as atividades produtivas desagregadas a quatro dígitos na qual a proximidade é medida pela distância entre dois bens diferentes. Para isso, em primeiro lugar, considera-se uma medida de concentração da produção de certo bem para cada região, denominada de relevância industrial relativa (RIR), a qual é dada por:

$$
R I R(c, i)=\frac{x(c, i)}{\sum_{i} x(c, i)} / \frac{\sum_{c} x(c, i)}{\sum_{i, c} x(c, i)}
$$

em quex(c,i) é o valor da produção do bem i na microrregião c. Se a medida de RIR é maior que 1, isso indica que o percentual de produção da microrregião naquele produto é maior que o percentual desse produto na produção do país. Nesse caso, podemos dizer que a microrregião é efetiva na produção desse bem. A partir de RIR, pode-se definir a proximidade entre os bens i e j, como:

$$
\varphi_{i j}=\min \left\{P\left(x_{i} \mid x_{j}\right), P\left(x_{j} \mid x_{i}\right)\right\}
$$

Para uma microrregião c, tem-se que:

$$
x_{i, c}=\left\{\begin{array}{c}
1 \text { se } R I R_{i, c}>1 \\
0 \text { em qualquer outrocaso }
\end{array}\right.
$$

(ii) $\quad P\left(x_{i} \mid x_{j}\right)$ é a probabilidade condicional da produção de bem i dado que a microrregião produz $\mathrm{j}$.

Assim, esta medida $\varphi_{i j}$ fornece uma ideia da densidade industrial, assim como de especialização em uma microrregião em um escopo de bens. Por 
sua vez, as duas medidas, RIR e proximidade, permitem fazer comparações entre as regiões, possibilitando conhecer a complementaridade/similaridade dos bens produzidos em cada uma. Trata-se, por outro lado, de uma forma de suprir a falta de dados de comércio entre as duas microrregiões que não são disponibilizados por nenhum organismo público. ${ }^{4}$

\section{Estrutura produtiva das microrregiões de São Paulo (SP) e Manaus (AM): especialização complementária}

Nesta seção, apresentam-se os resultados do indicador de relevância industrial relativa (RIR) para as duas microrregiões objeto do estudo. A fonte de dados utilizados é o número de trabalhadores setoriais, classificados de acordo a Classificação Nacional da Atividade Econômica (CNAE 2.0), da Relação Anual de Informações Sociais (RAIS), do Ministério de Trabalho e Emprego. Os resultados mostram a potencialidade de comércio entre as duas microrregiões, o que justificaria o investimento no transporte de cabotagem de qualidade.

\subsection{Incentivos fiscais e especialização produtiva: Manaus}

A microrregião de Manaus, localizada no estado do Amazonas, na região norte do Brasil, é especializada em fabricação de motocicletas e em vários segmentos do setor de eletroeletrônicos, com empresas de grande porte e expressiva participação do emprego em faixas inferiores de salários. Essa especialização é resultado da conformação da Zona Franca de Manaus (ZFM), instituída em $1967^{5}$ e prorrogada em 2014 até $2073^{6}$. Inicialmente concebida como polo exportador, atualmente a maior parte da sua produção é destinada ao mercado interno.

O modelo da ZFM baseia-se em benefícios tributários para as empresas ali instaladas ${ }^{7}$ e tem a intenção de ampliar a inserção internacional dos

4 Uma possibilidade de obtenção desses dados seria o aceso às bases da Receita Federal do ICMS, mas esses dados não estão disponíveis para pesquisa.

5 Decreto-Lei n²88 de 28 de fevereiro de 1967.

6 Emenda Constitucional 83.

7 Proteção aduaneira à produção de bens de consumo duráveis (reserva de mercado), incen- 
bens produzidos e o adensamento tecnológico do parque industrial. $\mathrm{O}$ objetivo da criação da ZFM foi e é a dinamização das forças produtivas nesse local como forma de reduzir o "custo Amazônia" (Galeano; Feijó, 2013).

A Suframa é uma das instituições que se destacam na execução das políticas de apoio à indústria, constituindo-se como principal braço executor das políticas do Governo Federal, financiando e articulando políticas de desenvolvimento regional de todos os clusters da região amazônica (Vieira Sá et al., 2010).

No geral, os incentivos fiscais aplicados conseguiram atingir o limiar necessário para provocar um deslocamento de capital suficientemente grande de outras regiões do Brasil, o que garantiu a industrialização regional e ampliou a participação de produtos nacionais no abastecimento de bens de consumo duráveis ao mercado interno. Existem, porém, algumas debilidades que, depois de mais de quarenta anos de proteção, devem ser salientadas.

Em primeiro lugar, não há exigência de contrapartida em termos de qualquer medida de eficiência produtiva (como, por exemplo, aumentos de produtividade ou inserção nos mercados externos de forma competitiva), assim como inexistem mecanismos de controle e avaliação. Em segundo lugar, segundo Lyra (1995), há uma carência em termos de articulações de políticas que resultassem em uma maior integração da região e também da ZFM com o restante da região Norte e do país.

A seguir, analisam-se os indicadores de especialização que permitem conhecer os setores nos quais a microrregião de Manaus se especializa e em quais existem complementariedades com a microrregião de São Paulo (cujos resultados são apresentados na próxima seção).

Analisando o indicador de RIR, percebe-se que no ano de 2013 a microrregião de Manaus apresenta indicador maior que a unidade em 58 classes setoriais do $\mathrm{CNAE}^{8}$ 2.0, e indicador maior que $10 \mathrm{em}$ dez setores, conforme apresentado na Tabela 1.

Os resultados indicam forte especialização em setores do complexo de equipamentos de informática, produtos eletrônicos e ópticos e na fabricação de outros equipamentos de transporte, exceto veículos automotores, em especial, motocicletas. Esses setores, segundo Galeano e

tivos ao investimento baseados no IPI, IRPJ, ICMS e cessão de lotes dotados de infraestrutura no Distrito Industrial de Manaus (Lyra, 1995).

8 Classificação Nacional da Atividade Econômica (IBGE). 
Feijó (2013), tiveram um bom desempenho em termos de produtividade do trabalho, quando comparados com o total do Brasil, com exceção do setor de fabricação de cronômetros e relógios e equipamentos ópticos (Divisão 33 CNAE).

Tabela 1 Indicador de relevância industrial relativa - Manaus 2013

\begin{tabular}{lr}
\hline Classe CNAE 2.0 (4 dígitos) & RIR \\
\hline Fabricação de motocicletas & 48.44 \\
\hline Fabricação de cronômetros e relógios & 42.51 \\
\hline Fabricação de aparelhos de recepção, reprodução, gravação e amplificação de áudio e vídeo & 35.50 \\
\hline Fabricação de pilhas, baterias e acumuladores elétricos, exceto para veículos automotores & 28.59 \\
\hline Fabricação de componentes eletrônicos & 25.35 \\
\hline Fabricação de aparelhos e equipamentos de ar-condicionado & 23.84 \\
\hline Fabricação de equipamentos de transporte não especificados anteriormente & 17.09 \\
\hline Fabricação de equipamentos e instrumentos ópticos, fotográficos e cinematográficos & 15.98 \\
\hline Fabricação de periféricos para equipamentos de informática & 13.23 \\
\hline Fabricação de artigos de cutelaria & 13.11 \\
\hline
\end{tabular}

Fonte: Elaboração dos autores com base nos dados da RAIS (2013).

Em relação aos tipos de aglomeração, existe evidência empírica que mostra que, assim como Manaus, cidades especializadas tendem a ser menores que cidades diversificadas, o que diminui os custos da superlotação (Farhauer; Kröll, 2012).

A matriz de proximidade, construída para setores CNAE com valor RIR $>1$, indica a existência de complementaridade com a microrregião de São Paulo, entre 58 setores a quatro dígitos. As proximidades mais relevantes são dadas entre os seguintes setores:

- Classes associadas à indústria de tecnologia da informação e comunicação, dentro das quais encontram-se: máquinas para escritório e equipamentos de informática, material eletrônico básico, equipamentos de telefonia e transmissores e equipamentos receptores de áudio e vídeo, totalizando dez classes do CNAE. Em relação a este setor, Kubota (2009) ressalta que mesmo apresentando indicadores de esforço tecnológico mais elevado que a média da indústria em geral, o setor apresenta duas grandes fraquezas: forte coeficiente de penetração de importação de componentes e dependência de padrões tecnológicos mundiais. A forte especialização e o adensamento dentro desta cadeia é resultado direto dos incentivos fiscais 
concedidos para empresas que investem em $\mathrm{P} \& \mathrm{D}{ }^{9}$

- Setores da CNAE 27, fabricação de máquinas, aparelhos e materiais elétricos. Trata-se de um setor intimamente relacionado com o anterior, em que quatro classes CNAE apresentam indicador de proximidade elevado não apenas entre elas, mas também com as classes do item anterior.

\subsection{Aglomeração madura e especialização diversificada: São Paulo}

A microrregião de São Paulo encontra-se no principal centro econômico do Brasil, concentrando boa parte das atividades industriais, financeiras e inovativas do país, além de apresentar ampla infraestrutura urbana, social, educativa e de transportes.

A concentração da atividade econômica no estado de São Paulo possui raízes históricas detalhadas, por exemplo, por Cano (1977). O autor explica a concentração desde a ótica de demanda determinada por dois momentos:o primeiro é a concentração por "estímulo", que compreende o período da primeira guerra mundial em que a indústria paulista atende à demanda de todo o país. O segundo momento, chamado de "necessidade", é datado na década de 1920 e diz respeito ao esforço de viabilizar o processo de acumulação, via conquista de mercados externos (Cano, 1977). A concentração, possibilitada em um primeiro momento pela demanda do próprio estado, é validada posteriormente pela crescente interação com os mercados externos e internos.

Trabalhos posteriores, como os de Diniz (1994) e Domingues et al. (2006), apontam para uma tendência de relativa desconcentração da atividade econômica da indústria e dos serviços da microrregião de São Paulo para municípios na franja deste grande centro industrial, e de outros estados. Essa desconcentração relativa é consequência de políticas regionais, da procura de recursos naturais em novas regiões e da unificação do mercado nacional por meio da infraestrutura de transportes e comunicação (Diniz, 2009).

É possível inferir, por sua vez, que também começaram a operar as deseconomias da aglomeração (crowding effects), o que é demonstrado por

9 A Lei 8248/91 garantia isenção do IPI para as empresas localizadas na ZFM que investissem $5 \%$ do faturamento bruto em $\mathrm{P} \& \mathrm{D}$ dentro do país e observassem as diretrizes do Processo Produtivo Básico (PPB), que determina as etapas mínimas que devem ser realizadas dentro do país. 
Galeano e Feijó (2013) - que através de uma análise shift-share chegam à conclusão de que quase $90 \%$ da queda da produtividade da região sudeste na década de 2000 é explicada pelo componente regional.

Quanto aos resultados, em 2013, a microrregião de São Paulo apresenta indicador de relevância industrial (RIR) relativa maior que a unidade para 117 classes CNAE 2.0, o que indica uma indústria com relevância nacional muito mais diversificada do que no caso da microrregião de Manaus. $\mathrm{Na}$ Tabela 2, são apresentadas as atividades produtivas com maior RIR da microrregião de São Paulo (RIR>3).

Tabela 2 Indicador de relevância industrial relativa - São Paulo 2013

\begin{tabular}{lr}
\hline Classe CNAE 2.0 (4 dígitos) & RIR \\
\hline Fabricação de caminhões e ônibus & 6.68 \\
\hline Fabricação de embalagens de vidro & 6.32 \\
\hline Metalurgia do cobre & 6.14 \\
\hline Fabricação de mídias virgens, magnéticas e ópticas & 3.65 \\
\hline Fabricação de margarina e outras gorduras vegetais e de óleos não comestíveis de animais & 3.65 \\
\hline Fabricação de fibras artificiais e sintéticas & 3.65 \\
\hline Fabricação de peças e acessórios para veículos ferroviários & 3.65 \\
\hline Fabricação de material elétrico para instalações em circuito de consumo & 3.56 \\
\hline Serviços de acabamentos gráficos & 3.52 \\
\hline Fabricação de aparelhos eletrodomésticos não especificados anteriormente & 3.38 \\
\hline Fabricação de tintas de impressão & 3.32 \\
\hline Fabricação de pneumáticos e de câmaras-de-ar & 3.25 \\
\hline Fabricação de produtos petroquímicos básicos & 3.17 \\
\hline Fabricação de máquinas e equipamentos para saneamento básico e ambiental & 3.12 \\
\hline Fabricação de máquinas e equipamentos para as indústrias de celulose, papel e papelão & 3.04 \\
\hline e artefatos & \\
\hline Fabricação de linhas para costurar e bordar & 3.02 \\
\hline Fabricação de válvulas, registros e dispositivos semelhantes & 3.01 \\
\hline Fabricação de produtos químicos orgânicos não especificados anteriormente & 3.00 \\
\hline
\end{tabular}

Fonte: Elaboração dos autores com base nos dados da RAIS (2013).

Os resultados desse indicador permitem que se denomine a estrutura produtiva da microrregião como "especialização diversificada", sabendo-se que além de diversificada, mais de cem setores apresentam coeficiente que indica concentração significativa de trabalhadores quando comparada com 
aquela da média do país. Este tipo de aglomeração apresenta conjuntamente vantagens de economias de diversificação e especialização, combinando os benefícios de maior produtividade das estruturas especializadas com as vantagens de uma estrutura diversificada, como, por exemplo, o efeito de cross-fertilisation (Farhauer; Kröll, 2012); isto é, os efeitos spillovers são coordenados, dado que ocorrem entre setores relacionados.

A matriz de proximidade de São Paulo mostra com destaque a sinergia entre os seguintes setores $\mathrm{CNAE}$, que se beneficiam da proximidade de firmas a montante e a jusante e de um mercado de trabalho qualificado e especializado:

- Divisões 26, 27e 28 CNAE: Existem fortes spillovers e complementaridades entre as classes das três divisões que incluem fabricação de equipamentos de informática e produtos eletrônicos (divisão 26), máquinas, aparelhos e materiais elétricos (divisão 27) e máquinas e equipamentos (divisão 28). No caso de São Paulo, 25 classes destas divisões apresentam proximidade entre elas, o que indica forte especialização em bens intensivos em tecnologia sofisticada.

- Proximidade entre setores relacionados à cadeia de valor de produtos têxteis e confecção de vestuário: 7 setores de duas divisões da CNAE com importante coeficiente de proximidade entre eles.

- Cadeia produtiva do setor químico que inclui as classes de produtos petroquímicos básicos, químicos e farmoquímicos. Trata-se de 14 classes que compartilham a mesma base; isto é, a conversão de matérias-primas orgânicas e inorgânicas por meio de processos químicos ou biotecnológicos.

- Divisão 32 CNAE: fabricação de produtos diversos como artigos de joalheria e bijuteria, instrumentos musicais, artefatos para pesca e esporte, brinquedos e jogos, instrumentos e materiais para uso médico, odontológico e artigos óticos, entre outros. $O$ resultado pode ser justificado principalmente pelas economias associadas ao acesso ao grande mercado consumidor da região sudeste. ${ }^{10}$

\subsection{Complementaridades, interações e a eficiência do transporte}

Comparando os indicadores das duas microrregiões, pode-se afirmar que as microrregiões contam com "especialização complementária". Consideran-

$10 \bigcirc$ mesmo resultado aparece para a divisão 18 (impressão e reprodução de gravações). 
do as 22 atividades com maior concentração de trabalhadores em Manaus (indicador RIR $>3$ ), apenas duas atividades têm indicador maior que três também para a microrregião de São Paulo. ${ }^{11}$ Considerando as atividades com indicador RIR $>1$ em Manaus, menos da metade das atividades contam também com indicador RIR $>1$ em São Paulo. $O$ que indica que existem fortes complementaridades nas indústrias das duas microrregiões, o que favorece o comércio entre elas (e, em grande medida, o comércio Sudeste-Norte).

Quando é analisada a complementaridade no sentido Sudeste-Norte, um resultado similar aparece. São Paulo conta com dezoito classes CNAE com RIR $>3$. Destas, apenas duas detêm indicador maior que 3 em Manaus e mais três aparecem com indicador maior que 1 . Das 114 atividades com RIR $>1$ em São Paulo, 28 também apresentam indicador maior que 1 em Manaus.

Levando em contaque não contamos com dados de comércio entre as microrregiões, dois trabalhos recentes mostram a importância do intercâmbio de bens entre os estados de São Paulo e Amazonas (Guilhoto; Sesso Filho, 2010), assim como o intercâmbio entre microrregiões (Faria; Haddad, 2011) é de grande importância, tanto para uso intrassetorial, como para consumo privado e de governo. Em relação à matriz de usos, destacam-se os seguintes setores em termos de interligações, para cada um dos estados:

- Origem Manaus - Destino São Paulo: o setor de metalurgia do Amazonas provê insumos para os setores de metalurgia, máquinas e equipamentos, material elétrico e eletrônicos e material de transportes de São Paulo. O setor de material elétrico e eletrônicos conta com fortes interligações com os setores de máquinas e equipamentos, material elétrico e eletrônico e material de transportes. O setor de madeira é fornecedor fundamental do setor paulista de mobiliário e papel. Finalmente, o setor de outros químicos e fármacos tem importantes laços com os setores de material elétrico e eletrônico, material de transporte e mobiliário e papel.

- Origem São Paulo - Destino Manaus: o setor de material eletrônico de Manaus é fortemente dependente dos insumos provenientes de São Paulo, em especial dos setores de metalurgia, máquinas e equipamentos, material elétrico, mobiliário, refino de petróleo e coque e outros químicos e fármacos. Por sua vez, o setor de material de transporte (especialmente motocicletas), se vale dos insumos vindos dos setores paulistas de metalurgia, material de transporte e outros químicos.

11 Fabricação de aparelhos eletrodomésticos não especificados anteriormente e fabricação de material elétrico para instalações em circuito de consumo. 
O transporte dos insumos e produtos entre as duas microrregiões ocorre principalmente pelo modal rodo-fluvial, dentro do eixo Norte-Sudeste ${ }^{12}$, totalizando 2,9 mil quilômetros de rodovia e 3,0 mil quilômetros de hidrovia. Uma alternativa ao trecho rodoviário é o modal de cabotagem, ligando os portos da região Norte ao porto de Santos. Tomando-se o exemplo de transporte de cargas conteinerizadas - que representa fundamentalmente a carga de produtos industrializados - tem-se, com base em dados da ANTAQ (2014), que a movimentação de cargas com origem (ou destino) em Manaus e destino (ou origem) em Santos alcançou, em 2014, 1,7 milhões de toneladas, o que representa cerca de $7,5 \%$ do total movimentado (embarques e desembarques) de contêineres em cabotagem no Brasil (caracterizando esta $\mathrm{OD}$ como uma das mais importantes no transporte de cabotagem). Diversos estudos mostram o significativo ganho de eficiência e potencial econômico das rotas de cabotagem (CNT, 2014), dado que as maiores concentrações populacionais encontram-se em centros urbanos próximos à costa oceânica.

É bastante reconhecido que o transporte de cabotagem no Brasil ainda requer mudanças estruturais que possam resultar em ganhos de competitividade deste modal. As mudanças demandadas são de natureza institucional, legal e de estímulo a investimentos e podem ser elencadas como segue: i) aumento da frota da Marinha Mercante brasileira; ii) aumento da oferta e frequência de embarcações no sentido Norte-Sudeste e Norte-Sul; iii) aumento e melhoria da infraestrutura portuária; iv) melhora da acessibilidade de navios com maior calado e comprimento; v) aumento das áreas retroportuárias; vi) ampliação dos terminais especializados (frigoríficos, contêineres, granéis, petroquímicos e agrícolas); vii) a diminuição da burocracia portuária; e viii) o aumento do número de trabalhadores especializados (CNT, 2014). Essas inovações permitiriam obter tarifas de fretes mais competitivas, diminuição de tempo na operação de movimentação nos navios, diminuição de custos de sobre-estadia (demurrage), prazos de entrega menores e maior frequência, o que atrairia maior nível de carga provenientes dos setores de bens de consumo.

Como já foi analisado na Seção 2.2 (veja-se especialmente a Figura 2), inovações no setor de transportes -como ampliação da infraestrutura e

12 Liga as regiões Norte e Sudeste, passando pela região Centro-Oeste, com extremidades localizadas no encontro dos rios Madeira e Amazonas, nas proximidades de Itacoatiara (AM) e no município de Santos(SP) (CNT, 2014). 
ganhos de eficiência, acompanhados de redução de fretes - podem afetar a distribuição geográfica das atividades econômicas. Assim sendo, para uma dada estrutura produtiva, investimentos em infraestrutura geram externalidades que se difundem especialmente pela área de influência desse investimento. Então, o aumento da extensão e da eficiência da infraestrutura relacionada ao comércio dos bens gerados pela aglomeração produtiva de Manaus poderia resultar em uma condição mais sustentável deste arranjo produtivo, reduzindo a dependência dos subsídios públicos à produção.

\section{Aplicação: um modelo de escolha do modal de transporte}

Uma vez que os resultados indicam que as microrregiões de São Paulo e Manaus têm produções que podem ser consideradas complementares, que existe forte intercâmbio de insumos e bens finais entre essas aglomerações (Guilhoto; Sesso Filho, 2010; Faria; Haddad, 2011), e que tais ligações ocorrem por um sistema de transportes que pode ser melhorado em termos de eficiência (CNT, 2014), resta conhecer quais são os determinantes da escolha empresarial entre os modais de transporte. $\bigcirc$ conhecimento e a avaliação das variáveis que condicionam essa decisão permitirão coordenar, a priorização de investimentos e políticas públicas de infraestrutura e institucionais.

\subsection{Estratégia metodológica}

Os modelos de escolha discreta utilizam as preferências dos indivíduos em relação a um conjunto de opções pré-definidas para estimar funções de utilidade, lidando com a expectativa de comportamento dos entrevistados frente a possíveis cenários em relação ao transporte (Ortúzar; Román, 2003). A estrutura do modelo de eleição discreta aplicado ao transporte de cabotagem tem como objetivo:

a) Comparar a atratividade do modal de transporte de cabotagem (alternativa pesquisada), em relação à alternativa existente (rodoviário). Dado que a alternativa de cabotagem tem um custo inferior, a migração de carga de uma para outra modalidade poderia representar uma mudança na 
conformação das aglomerações relativas Norte-Nordeste/Sul-Sudeste em geral. Esta hipótese segue a literatura que mostra que diminuições no custo de transporte geram mudanças no equilíbrio do padrão das aglomerações produtivas entre regiões (Takahashi, 2007; Behrens et al., 2009; Akamatsu et al., 2012; Ikeda et al. 2014).

b) Determinar parâmetros que definam a escolha dos usuários a partir dos atributos de cada alternativa. Neste sentido, procurou-se abranger todas as características obtidas em estudos anteriores (teóricos e empíricos). Dentro destes parâmetros, o preço do frete é referido como sendo o mais importante. A evidência mostra que a infraestrutura existente dos modais de transportes determina o valor do frete (Combes; Lafourcade, 2005). Trabalhos recentes mostram o impacto da estrutura de mercado no setor de transporte (em particular, em cada modal) na determinação dos preços (Behrens et al., 2009). Além de captar diferenciais nos atributos dos modais, as variáveis captam a heterogeneidade da escolha por parte das firmas - conforme a ideia de que essa heterogeneidade define situações de equilíbrio que não necessariamente podem ser consideradas ótimos do ponto de vista de mercado (Ottaviano, 2011).

c) Determinar parâmetros que definem a escolha dos usuários baseados nas características do processo produtivo e bens produzidos pelas empresas. Em primeiro lugar, considera-se uma variável dummy que indica a região geográfica da empresa (norte ou sudeste). Essa variável tenta captar o tamanho assimétrico das aglomerações consideradas, assim como o possível impacto de políticas regionais (Brülhart et al., 2012). Em segundo lugar, é considerado o tipo de produto transportado a partir de duas variáveis: uma variável dummy que indica se o setor de atividade é industrial ou de produção primária; e uma variável que indica o valor agregado pela atividade considerada (baixo, médio e alto). Para finalizar, considera-se o tamanho da empresa como relevante na determinação do tipo de aglomeração, assim como a solução de transporte escolhida pela empresa (Drucker; Feser, 2012).

A Figura 2 apresenta esquematicamente o modelo de eleição discreta entre transporte de cabotagem e transporte rodoviário aplicado a um conjunto de empresas usuárias em um dos modais no trecho em estudo. $\mathrm{Na}$ eleição de um modal de transporte, são ponderadas questões associadas às características dos diferentes modais, da própria empresa e dos insumos e produtos fabricados e comercializados. 
Figura 2 Estrutura do modelo de eleição discreta aplicado ao transporte de cabotagem

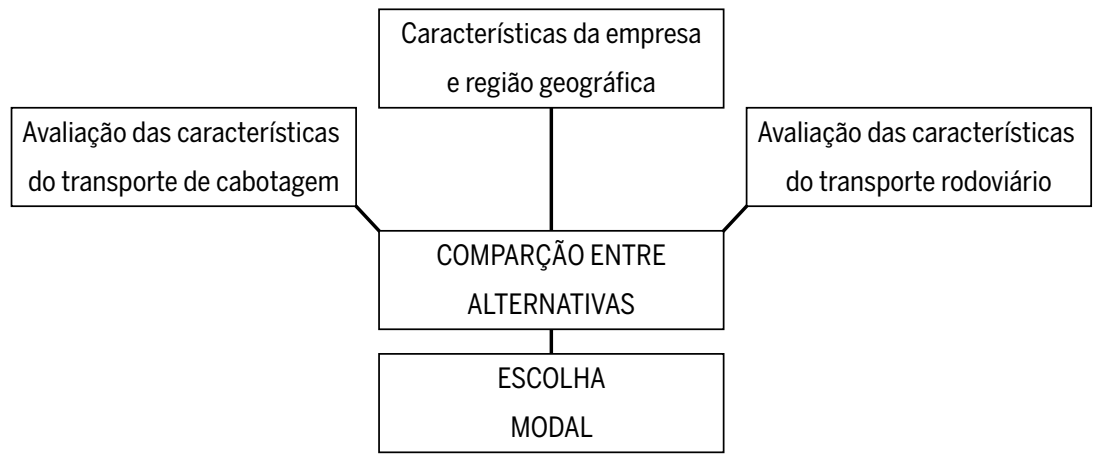

Fonte: Elaboração dos autores .

Considerando o modelo de escolha e as características das variáveis determinantes, pode-se especificar um modelo logit misto. A amostra é composta por 38 empresas $(q=1, \ldots 38)$ das microrregiões de Manaus e São Paulo. No desenho amostral, foram considerados os tamanhos relativos das microrregiões, assim como os setores com maior susceptibilidade de utilizar transporte de cabotagem. A amostra pode ser considerada representativa no que diz respeito ao tamanho das microrregiões consideradas, assim como dos setores econômicos representativos destas. Nas entrevistas, essas empresas escolhem entre $t$ alternativas (cabotagem e rodoviário) com T situações de escolha (dadas por diferentes níveis das variáveis). Cada empresa leva em conta o conjunto completo de alternativas possíveis, ordenadas (aleatoriamente) em cartões, e, então, escolhe a situação associada ao maior nível de utilidade.

A utilidade associada com cada alternativa i, avaliada por cada empresa q, na situação de escolha t, é representada por um modelo de escolha discreta com a expressão de utilidade dada pela seguinte equação:

$$
U_{i q}=\beta_{q}^{\prime} x_{i q}+\left[\eta_{i q}+\varepsilon_{i q}\right]
$$

onde $x_{i q}$ é um vetor de variáveis explicativas observadas, que inclui:

a) Atributos das alternativas: frete, transit time, regularidade e confiabilidade.

b) Características socioeconômicas das empresas: tamanho da empresa, setor de atuação (indústria ou serviços), valor agregado do bem produzido 
e comercializado, número de estados onde a empresa atua e número de filiais (linhas de produção e centros de distribuição).

c) Descrição do contexto: região de localização da empresa, que inclui as regiões norte e sudeste.

$\beta_{q}^{\prime}, \eta_{i q}$ e $\varepsilon_{i q}$ são influências estocásticas não observadas. No contexto do modelo logit, em geral, assume-se que o componente de erro é independente e identicamente distribuído (IID). O modelo logit misto permite diminuir a restrição particionando o componente estocástico em duas partes. Assim, $\eta_{i q}$ é um termo aleatório com média zero, cuja distribuição entre indivíduos e alternativas depende dos parâmetros subjacentes e dados observados relacionados à alternativa $i$ e indivíduos $q$. $\varepsilon_{i q}$ é um termo aleatório com média zero, que é IID entre as alternativas e não depende dos parâmetros subjacentes ou dados. ${ }^{13}$

Para um dado valor de $\eta_{i q}$ com densidade dada por $f\left(\eta_{i q} \mid \Omega\right)$, a probabilidade condicional da escolha $i$ é logit, sempre que o termo de erro remanescente seja IID:

$$
L_{i q}\left(\beta_{q} \mid \eta_{i q}\right)=\frac{\exp \left(\beta_{q}^{\prime} x_{i q}+\eta_{i q}\right)}{\sum_{j} \exp \left(\beta_{q}^{\prime} x_{i q}+\eta_{i q}\right)}
$$

A probabilidade incondicional é o logit integrado em (2) para todos os valores de $\eta_{i q}$, ponderados pela densidade de $\eta_{i q}$ :

$$
P_{i q}\left(\beta_{q} \mid \Omega\right)=\int_{\eta_{i q}}\left(\beta_{q} \mid \eta_{i q}\right) f\left(\eta_{i q} \mid \Omega\right) \eta_{i q}
$$

O modelo é chamado logit misto uma vez que a probabilidade é uma mistura de logits $\operatorname{com} f$ como distribuição mista. A probabilidade não exibe a característica questionável de independência de alternativas irrelevantes (IIA) (Hensher; Greene, 2003).

\subsection{Resultados do modelo: determinantes da escolha do modal de transporte}

Os resultados do modelo de escolha discreta estão na Tabela 3. Todos os

13 Para uma análise detalhada do componente do erro e a sua distribuição, no modelo logit, veja-se Hensher e Greene (2003). 
coeficientes apresentam o sinal esperado assim como significância estatística. O pseudo- $\mathrm{R}^{2}$ de Mc Fadden, utilizado para modelos de escolha discreta, apresenta um valor de $48,33 \%$, mostrando que o modelo completo apresenta um ajuste melhor que o modelo-intercepto.

Os coeficientes relacionados a atributos dos modais de transporte apresentam os seguintes resultados:

- O valor do frete de cabotagem apresenta sinal negativo, como esperado, o que significa que à medida que diminui o preço do frete de cabotagem, a probabilidade de troca de modal (do rodoviário para cabotagem) aumenta.

- No caso do transit time, o sinal também é negativo, o que indica que à medida que aumenta o tempo de transporte via cabotagem entre origem e destino, diminui a probabilidade de ser utilizado o modal de cabotagem (em relação ao rodoviário). Maior transit time implica maior necessidade de planejamento nas firmas e o requerimento de manter maiores níveis de estoque junto ao destino, o que reduz a eficiência do uso do modal.

- $O$ atributo regularidade apresenta o coeficiente com maior magnitude, assim como sinal positivo, o que implica que se a navegação de cabotagem tiver a disponibilidade de um maior número de saídas semanais, a probabilidade de utilização desse modal (em detrimento do rodoviário), aumenta. Assim, a maior regularidade constitui-se como o principal atributo que as empresas ponderam quando tomam a decisão de utilização de um ou outro modal.

- Por último, a confiabilidade do modal - em relação, por exemplo, a atrasos de prazo de entrega - é um fator que contribui positivamente para aumentar a probabilidade de escolha do modal de cabotagem (comparado com o rodoviário).

- Com relação às características das empresas, da região e dos produtos fabricados, os determinantes que contribuem para a transferência do modal são os seguintes:

- O tamanho da empresa; isto é, à medida que o tamanho aumenta, a empresa tende a ter um maior número de filiais (linhas de produção ou centros de distribuição). Com isso, os lotes médios de transporte são menores, aumentando a eficiência do modal rodoviário e diminuindo a probabilidade de transferência para a cabotagem. Destaca-se que o tamanho da empresa é medido pelo número de empregados. ${ }^{14}$ Este resultado pode também ser justificado pelo fato de que empresas grandes são mais pro14 Outra variável que poderia ser utilizada para medir tamanho é a receita da empresa, mas algumas delas optaram por não fornecer essa informação. 
pensas a optar por soluções de transporte próprias, a importar insumos de outros países (em lugar de insumos do resto do país) ou a partir de oferta interna, via integração vertical (Drucker; Feser, 2012).

Tabela 3 Resultados do Modelo Logit Misto - pesquisa de escolha discreta

\begin{tabular}{lrrrrr}
\hline Atributo & Coeficiente & Erro Padrão & t-valor & P-Valor \\
\hline Intercepto cabotagem & 5,3138 & 1,7016 & 3,1227 & ${ }^{* *} 0,0018$ \\
\hline Preço Frete & $-0,1298$ & 0,0483 & $-2,6892$ & ${ }^{* *} 0,0072$ \\
\hline Transit Time & $-0,4608$ & 0,1434 & $-3,0068$ & ${ }^{* *} 0,0026$ \\
\hline Regularidade & 1,4080 & 0,4683 & 2,6679 & ${ }^{* *} 0,0076$ \\
\hline Confiabilidade & 0,4350 & 0,0744 & 5,8446 & ${ }^{* * *} 0,0000$ \\
\hline Sudeste & $-1,3012$ & 0,6107 & $-2,1306$ & ${ }^{*} 0,0331$ \\
\hline Indústria & 0,2467 & 0,5716 & 0,4316 & 0,6660 \\
\hline Valor agregado & $-1,4738$ & 0,3997 & $-3,6869$ & $* * * 0,0002$ \\
\hline Número de filiais & $-0,4148$ & 0,2241 & $-1,8506$ & $.0,0642$ \\
\hline Número de estados & 1,8999 & 0,4664 & 4,0714 & ${ }^{* * *} 0,0000$ \\
\hline Tamanho da empresa & $-0,0004$ & 0,0002 & $-2,1288$ & ${ }^{*} 0,0333$ \\
\hline Observações & & & & 448 \\
\hline Verossimilhança & & & & $-150,56$ \\
\hline$X^{2}$ do teste Razão de verossimilhança & & & & 281,68 \\
\hline R de Mc Fadden & & & & 0,4833 \\
\hline
\end{tabular}

Fonte: Elaboração dos autores a partir dos resultados da estimação. Nota: Níveis de significância '***'0; '**'0,001; **'0,05; '*'0,05; "’0,10.

- O valor agregado dos produtos fabricados; isto é, quanto maior for o valor agregado dos produtos, menor a probabilidade de que a empresa opte pelo modal de cabotagem. Tal resultado pode ser atribuído à maior incerteza em relação aos prazos do modal, gerada por fatores burocráticos e pelo favorecimento dos navios de longo curso sobre os navios de cabotagem.

- O número de estados nos quais a empresa participa, através da venda de seus produtos. Essa variável tem um efeito positivo sobre a transferência de modal, do rodoviário para a cabotagem, uma vez que indica a pulverização geográfica da demanda e o aumento da importância dos custos de transporte.

- A variável dummy para a região da empresa. Essa variável binária procura captar características em relação a diferenciais na infraestrutura de transporte. Como o coeficiente é negativo (e o valor 1 é para São Paulo), tem-se a 
indicação de que a probabilidade de escolha da cabotagem diminui quando a empresa está sediada em São Paulo. Resultado que evidencia a melhor infraestrutura de transporte terrestre a partir de São Paulo (em especial em comparação com a disponível a partir de Manaus) e confirma o encontrado por Behrens et al. (2009), que mostram que quanto maior a aglomeração espacial, menos elástica é a demanda por serviços de transporte.

\section{Comentários finais}

O presente trabalho teve como objetivo evidenciar o grau de complementariedade entre duas aglomerações produtivas e mostrar a importância da escolha do modal de transporte entre essas duas regiões. As aglomerações estudadas foram as das microrregiões de São Paulo e Manaus, que se caracterizam por ter estruturas produtivas concentradas, porém assimétricas.

Em primeiro lugar, buscou-se traçar as características produtivas das aglomerações das duas microrregiões. No caso de São Paulo, trata-se de uma aglomeração produtiva madura, que começa a apresentar sinais de deseconomias de concentração. Pode-se denominar a estrutura apresentada nesta microrregião como especialização diversificada, dado que mais de 100 classes CNAE apresentam um coeficiente de Relevância Industrial Relativa (RIR) maior do que um. Já Manaus apresenta forte especialização em poucos setores. A análise da matriz de proximidade permite afirmar que as microrregiões apresentam estruturas de produção complementares - o que favorece as relações comerciais entre elas, tanto com o comércio de bens intermediários (intra e interindustrial) como através do intercâmbio de bens de consumo final.

A estrutura de transportes entre as duas microrregiões é complexa, e acontece por duas vias. A maior parte do comércio é através do modal rodo-fluvial e uma pequena parte utiliza o modal de cabotagem. Este último modal apresenta forte potencial de crescimento; e certas inovações de infraestrutura garantiriam ganhos de eficiência e queda de custos, resultando em maior competitividade para a aglomeração menor (Manaus), o que poderia tornar esse arranjo produtivo menos dependente de políticas públicas de subsídios.

Por fim, examina-se, para o caso de cargas conteinerizadas entre São Paulo e Manaus, os determinantes da decisão de transferência do modal 
rodo-fluvial para a cabotagem. A pesquisa de escolha discreta, realizada junto a empresas de diversos setores produtivos das duas microrregiões analisadas, mostra que esta transferência depende de características associadas à estrutura do setor de transportes, em especial aquelas relacionadas com custos (frete, transit time e confiabilidade) e com regularidade do serviço. Além disso, as características da estrutura produtiva também influenciam fortemente a possibilidade de transferência. Em particular, o valor agregado dos produtos fabricados e o tamanho da empresa são características que influenciam negativamente a mudança de modal.

\section{Referências}

AKAMATSU, T. TAKAYAMA, Y.; IKEDA, K. Spatial discounting, Fourier, and racetrack economy: a recipe for analysis of spatial agglomeration models. Journal of Economic Dynamics \& Control, n.36, p. 1729-1759, 2012.

ANTAQ - Agência Nacional de Transportes Aquaviários. SIG - Sistema de Informações Gerenciais. Acesso Público. [Base de Dados]. [s./d.]. Disponível em: <http://www.antaq.gov.br/ sistemas/sig/AcessoEntrada.asp?IDPerfil=23>. Acesso em: 28/01/2015.

AUDRETSCH, D.; FELDMAN, M. Knowledge Spillovers and the Geography of Innovation. Handbook of regional and urban economics, Elsevier, 2008.

BALDWIN, R.; FORSLID, R.;MARTIN, P.;OTTAVIANO, G. I. P.; ROBERT-NICOUD, F. Economic Geography and Public Policy. Princeton, NJ: Princeton University Press, 2003.

BALDWIN, R.; OKUBO, T. Heterogeneous firms, agglomeration and economic geography: spatial selection and sorting. Journal of Economic Geography, n.6, p. 323-346, 2006.

BEHRENS, K.; GAIGNE, C.; THISSE, J. Industry location and welfare when transport cost are endogenous. Journal of Urban Economics, v. 65, n. 2, p. 195-208, 2009.

BEHRENS, K.; PICARD, P. Transportation, freight rates, and economic geography. Journal of International Economics, v. 85, n. 2, p.280-291, 2011.

BEHRENS, K.;THISSE, J.-F. Regional economics: a new economic geography perspective. Regional Science and Urban Economics, n. 37 (4), p. 457-465, 2007.

BROWN, J.; LAMBERT, D.; FLORAX, J. The Birth, Death, and Persistence of Firms: Creative Destruction and the Spatial Distribution of U.S. Manufacturing Establishments, 20002006. Economic Geography, v. 89, n. 3, p.203-226, 2013.

BRÜLHART, M.; JAMETII, M.;SCHMIDHEINY, K. Do agglomeration economies reduce the sensitivity of firm location to tax differentials? The Economic Journal, n. 122, p. 1069-1093, 2012.

CANO, W. Raízes da Concentração Industrial em São Paulo. Hucitec: São Paulo, 1977.

COHEN, J.; PAUL, C. Agglomeration economies and industry location decisions: the impacts of spatial and industrial spillovers. Regional Science and Urban Economies, n. 35, p. 215-237, 2005. 
COMBES, P.; DURANTON, G.; GOBILLON, L., PUGA, D.; ROUX, S. The productivity advantages of large cities: distinguishing agglomeration from firm selection. Econometrica, v. 80, n. 6, p. 2543-2594, 2012.

COMBES, P.; LAFOURCADE, M. Transport costs: measures, determinants, and regional policy. Implications for France. Journal of Economic Geography, n. 5, p. 319-349, 2005.

CONFEDERAÇÃO NACIONAL de Transporte (CNT). Plano CNT de Transporte e Logística. Brasília: CNT, 2014.

DINIZ, C. Polygonized Development in Brazil: Neither Decentralization nor Continued Polarization. International Journal of Urban and Regional Research, v. 18, n. 2, p. 293-314, 1994.

DINIZ, C. Celso Furtado e o desenvolvimento regional. Nova Economia, v. 19, n. 2, p.227-249, 2009.

DOMINGUES, E.; RUIZ, R.; MORO, S; LEMOS, M. Organização territorial dos serviços no Brasil: polarização com frágil dispersão. In: DE NEGRI, J. A.; KUBOTA, L. C. Estrutura e dinâmica do setor de serviços no Brasil, IPEA, 2006.

DRUCKER, J.; FESER, E. Regional industrial structure and agglomeration economies: An analysis of productivity in three manufacturing industries. Regional Science and Urban Economies, n. 42, p.1-14, 2012.

FARHAUER, O.; KRÖLL, A. Diversified specialisation -going one step beyond regional economics' specialisation-diversification concept. Jahrbuch für Regionalwissenschaft, n. 32, p. 63-84, 2012.

FARIA, W.; HADDAD, E. Estimação das elasticidades de substituição do comércio regional do Brasil. TD Nereus, 01-2011.

FREITAS, L. A. S. Ferrovia Manaus-Boa Vista-Georgetwon - Alternativas do transporte para a Amazônia Ocidental. Rio de Janeiro, Câmara Brasileira de Jovens Escritores, 2009.

FUJITA, M. A monopolistic competition model of spatial agglomeration: Differentiated product approach. Regional Science and Urban Economics, n. 18, p. 87-124, 1988.

FUJITA, M.; KRUGMAN P.; VENABLES, A. The Spatial Economy. Cities, Regions and International Trade. Cambridge MA: The MIT Press, 1999.

GALEANO, E.; FEIJÓ, C. A estagnação da produtividade do trabalho na indústria brasileira nos anos 1996-2007: análise nacional, regional e setorial. Nova Economia, v. 23, n. 1, p. $9-50$.

GUILHOTO, J.; SESSO FILHO, U. Estimação da matriz insumo-produto utilizando dados preliminares das contas nacionais: aplicação e análise de indicadores econômicos para o Brasil em 2005. Economia \& Tecnologia, Ano 06, v. 23, 2010.

HAUSMANN, R.; KLINGER, B. The Structure of the Product Space and the Evolution of Comparative Advantage. CID Working Paper 146, 2007.

HENSHER, D.; GREENE, W. The Mixed Logit model: the state of practice. Transportation, n. 30, p.133-176, 2003.

IKEDA, K.; MUROTA, K; AKAMATSU, T.; KONO, T.; TAKAYAMA, Y. Self-organization of hexagonal agglomeration patterns in new economic geography models. Journal of Economic Behavior \& Organization, vol. 99, p. 32-52, 2014. 
JOHDO, W. Asymmetric Transportation Costs and the Home Market Effect. Theoretical Economics Letters, v. 3 n. 2, p. 81-84

KUBOTA, L. Indústria de Tecnologia da informação e comunicação. In: Estudos Setoriais de Inovação. ABDI, 2009.

KRUGMAN, P. Increasing returns and economic geography. Journal of Political Economy, n. 99, p. 483-499, 1991.

LYRA, F. Os incentivos Fiscais à Indústria da Zona Franca de Manaus: uma avaliação. Texto para Discussão n.371. Brasília: IPEA, 1995.

ORTÚZAR, J.; ROMÁN, C. El problema de modelación de demanda desde una perspectiva desagregada: el caso del transporte. EURE (Santiago), v. 29, n.88, p. 149-171, 2003.

OTTAVIANO, G. "New" new economic geography: firm heterogeneity and agglomeration economies. Journal of Economic Geography, n. 11, p. 231-240, 2011.

OTTAVIANO, G.; VAN YPERSELE, T. Market size and tax competition. Journal of International Economics, v. 67, n.1, p. 25-46, 2005.

PUGA, D. The magnitude and causes of agglomeration economies. Journal of Regional Science, n. 50, p. 203-219, 2010.

TAKAHASHI, T. Directional imbalance in transport prices and economic geography. Journal of Urban Economics, v. 69, n. 1, p. 92-102.

VENABLES, A. Equilibrium locations of vertically linked industries. International Economic Review, n. 37, p. 341-359, 1996.

VIEIRA SÁ, M.; OLIVEIRA JUNIOR, A. R.; DA COSTA, A. L. F.; EGAS, L. R. N. Análise das políticas para os APLs no Amazonas. In: Análise do Mapeamento e das Políticas para Arranjos Produtivos Locais no Norte, Nordeste e Mato Grosso e dos Impactos dos Grandes Projetos Federais no Nordeste. 2010

\section{Sobre o autor}

Eva Yamila da Silva Catela - eva.yamila@ufsc.br

Programa de Pós-Graduação em Ecologia da Universidade Federal de Santa Catarina - PPGECO/UFSC e Conselho Nacional de Pesquisas - CNPQ, Florianópolis, SC.

Fernando Seabra-f.seabra@ufsc.br

Programa de Pós-Graduação em Relações Internacionais da Universidade Federal de Santa Catarina - PPGRI/UFSC e Laboratório de Transportes e Logística - LabTrans, Florianópolis, SC.

\section{Sobre o artigo}

Recebido em 15 de fevereiro de 2015. Aprovado em 31 de março de 2016. 